\title{
OS VETORES DA SEGURANÇA EM ÁFRICA
}

\author{
Zeferino Cariço André Pintinho'
}

\section{A conjuntura africana}

A análise da segurança africana tem assumido um papel crucial no desenvolvimento teórico e empírico da ciência de Relações Internacionais Africanas. Esta intensidade deve-se, em grande medida, ao crescimento das abordagens ditas críticas. No entanto, estas mudanças surgem no âmbito de ampliar o espaço de análise mas também introduzir um importante salto qualitativo, do paradigma do vetor da segurança africana.

Embora o seu posicionamento no contexto internacional não constituía uma grande influência em termos de desenvolvimento económico, África é vista como um ator estratégico das Relações Internacionais com diferentes zonas de principais predominações.

Afigura-se como o continente berço da humanidade cicatrizado, por um lado, por um passado colonial imposto pelas potencias ocidentais que a dividiu e a esmigalhou deixando-a com uma pesada herança colonial, por outro lado, transporta em si o peso da maior balança de conflitos jamais vista na história da humanidade acrescida do volume do índice de pobreza, analfabetismo, doenças crónicas e um catálogo precário de modelos políticos de governação que se converteu numa competição de gestão politica "ditatorial por parte da maioria dos Estados.

Não obstante a isso, a configuração dos 54 Estados Africanos como atores da sociedade internacional, dos quais 53 são membros da União Africana, integra uma pluralidade sistémica de paradigmas que a guiam e a conservam no contexto da segurança africana.

Assim, afirma-se que a África contemporânea de uma maneira espe-

I Professor na Universidade Privada de Angola (UPRA) e no Instituto Superior Politécnico Inocêncio Nanga (ISPIN) e membro do Centro de Investigação em Ciência Política da Universidade de Évora. E-mail: zecapi@yahoo.com.br 
cífica "surgiu dum conjunto de Estados delimitados por fronteiras criadas por Estados colonialistas para sua comodidade administrativa sem considerar as realidades étnicas ou Estados pré-existentes (Tshiyembe 20I4, II). Neste caso, os Estados colonizadores trataram-na, em último caso, como um "território vazio que eles partilharam em função dos seus interesses (Action I998, 287).

Por conseguinte, ela continua a ser o campo de competição entre as potências e as empresas mineiras e petrolíferas, mas as ocupações territoriais diretas desapareceram, os competidores diversificaram-se e as formas de competição alteraram-se. Numa conceção realista, não há prosperidade duradoura sem poderio militar nem influência estratégica (Action I998, 287).

Deste ponto de vista, os fracos indicadores geoeconómicos juntam-se à fragilidade dos indicadores militares (formato dos exércitos, ausência de posse de armas nucleares e diplomáticos, fraco peso dos votos nas organizações internacionais) para fazer dos Estados africanos potências negligenciáveis, secundárias ou quase-potências ${ }^{2}$. No entanto, no contexto da modernidade apresenta-se com um desvio abismal de infraestruturas face a multiplicidade de escassez de instituições fortes capazes de competirem e elevarem a imagem diferente do continente.

Esta atuação colonial deixou sequelas inconscientes no posicionamento do continente africano que a seguir a esta fase não obteve uma estratégia consciente para o desenvolvimento de acordo com o redimensionamento da nova geopolítica mundial. No entanto, desde a sua autonomia, a fragmentação permanece inalterada e qualquer tentativa de reagrupamento e criação de uma enorme unidade resultou num fracasso.

Assim, Ruth B. Collier sustenta que a independência representou uma crise de gestão para os novos líderes políticos que foram confrontados com a necessidade de consolidação das suas posições através da busca de coesão entre as diferentes fações de elites em disputas e a necessidade de busca de apoio popular. Neste contexto os regimes multipartidários foram substituídos pelos regimes de partido único ou militares que permitiam a melhor satisfação dos interesses das novas elites dirigentes africanas (Collier I982).

Deste modo começou-se a construir uma nova identidade de construção de uma África diferente aonde "as questões culturais e a história, a luta pela riqueza e prestígio e as vicissitudes relacionadas com a pobreza e escassez de recursos contribuíram para a constituição de formas autoritárias de governação em África” (Fatton I990, 445).

Enquanto os denominados vencedores da Guerra de 1939/45 criaram

2 Potência: conceito relacional e dinâmico, que integra os recursos materiais (exército, finanças, população, recursos) e imateriais (ideologia, informação) de que dispõem os Estados. 
imediatamente um projeto de requalificação para a Europa e desenvolveram modelos de democracia como instrumentos pacificadores da sociedade, em África, o contorno da solidariedade não surtiu efeito, o sonho do progresso, das infra-estruturas, materializou-se num ato de deslembrança, de abandono real e passou a ser desconsiderada como o berço da benevolência para o continente dos "últimos mil milhões da pobreza - conforme afirma Paul Collier $(2007,5)$.

É importante considerar que a complexidade do novo sistema e abrangência dos novos regimes que se instaurou, Diamond considera que este facto deveu-se sobretudo porque os novos regimes enfrentavam uma fraqueza de autoridade do Estado, agravada por um outro conjunto de obstáculos históricos e estruturais, entre os quais se destacam as divisões étnicas, o fraco sentido de pertença à nação, a fragilidade das instituições políticas estabelecidas com pouca experiência, a ausência da capacidade técnica e de gestão ao nível indígena, a dependência económica extrema e as expectativas populares revolucionárias geradas pelas lutas pelas independências (Diamond I988, 32).

Contudo, desenvolveram-se normas de toda a espécie, desde a ditadura a golpes de Estado sucessivos, a não alternância do sufrágio universal ou do poder politico. Alternativamente e em continuidade, a promoção da paz e o desenvolvimento sustentável constituem um desafio a segurança africana (Diamond i988, 32).

Neste contexto estavam criadas as condições desfavoráveis à democratização e favoráveis, sim, ao surgimento de regimes autoritários nos estados africanos pós independência (Chabal and Daloz I999, 20).

Quase toda a África subsariana conheceu problemas similares em relação às propostas de Estado-nação nas repúblicas que se instauraram durante os dias das suas emancipações. De forma condensada, Feliz Gaeta observa que:

Com exceção das Ilhas Maurícias, desde o Mali até Madagáscar passando pelos países da África do Oeste Níger, Benim, Togo, Costa do Marfim, Nigéria, Senegal, Chade e da antiga África belga Zaire, Ruanda e Burundi» da África do Leste e do Oceano Índico Uganda, Tanzânia, Quénia, Comores e Madagáscar, da África Austral Zâmbia, Zimbabwe, Moçambique, Lesotho, África do Sul e Angola, como países, têm sabido gerir os seus sistemas político-parlamentares e liberais deixados pelo antigo poder colonial embora em todos estes países continuem a verificar-se formas idênticas de contestações (Gaeta I994, 713-729) (Tradução do autor).

Desde os finais do pluralismo político dos primórdios da década de I960, ocorreram vários golpes de Estado em África, que estabeleceram um 
mapa geoestratégico à mercê da Guerra Fria, fator de desestabilização das vontades populares africanas na construção dos seus modelos de Estado Nação e, por conseguinte, "transformaram a envolvência do poder político numa chefia de Estado (Tshiyembe 20I4, I5).

Com efeito, o continente passou a ser caraterizado por paradoxos incontornáveis de um sistema bloqueado na sua transição marcado por algum afastamento entre a estrutura institucional-normativa e a materialidade concreta; por conflitos e tensões entre o tradicional e o contemporâneo e entre e o real e o aparente; pela oposição entre a encantadora fortaleza do "Leviathan" e a sua fragilidade inerente; e por uma projeção bidirecional do local e do externo (Cilliers e Sisk 20I3).

Esta imagem de África justifica-se, entre outras razões, porque os mesmos paradigmas que legitimaram o tráfico de escravos e a colonização europeia continuam a residir no pensamento de muitos estudiosos daquelas ciências (Hugon 2009).

Contudo, Gilberto Veríssimo examina este quadro anacrónico como resultado de fatores considerados de:

[...] arquétipos, propagados pelos médias internacionais mais relevantes e apresentam geralmente as populações africanas como: o bárbaro, o inferior contra o qual é preciso proteger ou o qual é preciso civilizar, importando os benefícios das religiões reveladas, da ciência e das instituições; a criança, que necessita ser educada, atrasada na evolução da humanidade, diante do qual a mãe-pátria tem um papel educador, ou o qual ainda não está pronto para a democracia; o bom selvagem, do "superior" que vive em comunidades solidárias, em harmonia com a natureza, e que é preciso preservar; o irmão, nosso semelhante, com o qual é preciso cooperar; o estrangeiro que não podemos compreender e cuja diferença nos torna, em último caso, indiferentes; o escravo acorrentado que necessita ser libertado de seu dono e de seus grilhões; ou o pobre que necessita de assistência ou ajuda para se desenvolver (Veríssimo 2013, 30).

É de facto interessante a maneira como Gilberto Veríssimo teoriza o sustentáculo da imagem de África, com peculiaridade da sua instrumentalização. Nesta análise atraente de Gilberto interessa-nos sublinhar o papel dos médias das principais agências internacionais que contradizem a forma de gestão do poder em África e o seu índice de subdesenvolvimento, caracteriza-

3 Leviatã ou Matéria, Forma e Poder de um Estado Eclesiástico e Civil, comumente chamado de Leviatã, é um livro escrito por Thomas Hobbes e publicado em I65I. Ele é intitulado em referência ao Leviatã bíblico. 
do como insuficiente para exprimir o atual paradigma dos tempos modernos, pois que, a imagem definida como visão ou percepção de África persiste na respetiva consciência condizendo necessariamente a uma representação fiel da realidade africana.

Este quadro de conflitualidade, aliado ao subdesenvolvimento endémico de algumas regiões e países em África, acentua a fragilidade dos Estados e das próprias sociedades, constituindo um desafio maior à paz duradoura, ao desenvolvimento sustentável e aos direitos do homem, situações que estão a comprometer os Objetivos de Desenvolvimento deste continente no milénio corrente (Nação e Defesa 20I2, 6).

Entretanto, não é estranho que os problemas de segurança mais autóctones de África, ainda que similares aos que afetam outras regiões, se adicionem, através da conexão global projetada sobre a região, os grandes problemas mundiais de segurança e uma panóplia de questões recobertas pelo seu expandido conceito (Moller 2009).

Atualmente, esses problemas abrangem não só a tradicional segurança do Estado em relação aos seus congéneres, mas igualmente a segurança dos seus cidadãos, muitas vezes fazendo contrapor um vetor ao outro por forma a se precaver dos respetivos danos ${ }^{4}$.

No entanto, quando o povo africano afirma, na sua linguagem chã, que "por mais quente que seja a água da fonte, ela não coze o seu arroz , enuncia, com chocante simplicidade, um princípio fundamental não só da física como da ciência política. Pois, sabemos com efeito que a orientação do desenvolvimento dum facto em movimento seja qual for o seu condicionamento exterior depende principalmente das suas características internas para transformar a sua própria realidade com base no seu conhecimento concreto e nos esforços e sacríficos próprios (Cabral 2008, I74).

De facto, a inserção geoestratégica da segurança africana apela a uma articulação entre a centralização da opção interna/externa da cooperação, que se traduz no desenvolvimento das relações com os países vizinhos e com os parceiro sestratégicos.

Perante o lastro de variados e incalculáveis conflitos num argumento político e culturalmente dissemelhante, a tentativa de edificação de uma política de segurança que fundamente a mobilização de indivíduos e de meios suscita a interplação sobre as bases políticas, legais e morais que permitam escorar a ação e conferir lhe alguma medida de sucesso para além da análise

4 Ver a perspectiva adotada e as temáticas assinaladas em William, Paul. 2008. Security Studies: An Introduction. London: Routledge, e no estudo clássico de Buzan, Barry, Ole Wæver e Jaap de Wilde. I997. Security: A New Framework for Analysis. Boulder: Lynne Rienner. 
subjetiva das vantagens da pacificação e da segurança, que, por exemplo não são claramente repartidas por quem as tira fação dos conflitos ou se foi deixando complicar numa dinâmica de violência para que não vislumbra qualquer saída (Nação e Defesa 20I2, I6).

O Almirante A. Sanguinetti reconhece que a fusão entre antagonismos internos e externa suscita a confusão entre as inquietações legítimas de defesa e de segurança, entre as incumbências do exército e da polícia, induzindo assim a transformação progressiva dos polícias em verdadeiros exércitos, e formando, paralelamente, exércitos para intervirem internamente, violando a sua ética normal, sob a desculpa de defender a nação (Sanguintetti ig85, 498).

Noutros termos, ao associar a segurança nacional à promoção dessa doutrina nefasta a nível do sistema de valores fundamentais, o poder africano desencaminhou inteligências, patriotismos e intensas devoções (Tshiyembe 20I4, I9).

Ao longo de décadas, atestaram se lavouras de veemência e de morte, isto é, que fazem da violência uma norma de declaração individual e grupal e que, viciosamente, aqui e além, parecem comprovar a necessidade de uma governação despótica, de força, para a estabilização política e social e para a contenção de conflitos, horizonte pelo qual clamam pessoas exauridas por catástrofes e violências e, arriscaríamos dizer, pela prevalência de discursos e atitudes beligerantes (Nação e Defesa 20I2, I6).

A tentativa de compreensão da realidade factual permite concordar com a linhagem de alguns teóricos que defendem que o problema central está no Estado em África. A aplicação das conceções teóricas do Estado à África colocou problemas que bloquearam o lugar do continente na teoria das Relações Internacionais (Veríssimo 20I4, 3I).

A questão do Estado neo-patrimonial de debilidade da sociedade civil que se caraterizou durante os debates do período pós-independência sobretudo dos anos de $1980 / 90$ até à questão do regime de governação do ano 2000 provocou sérios problemas aos Estados em África, influenciando deste modo as implicações em como se entender as teorias das relações internacionais africanas e o lugar que elas ocupam (Veríssimo 20I4, 3I).

Neste contexto, a eficácia de todo o sistema de segurança regional africano é afetada pela fragilidade do Estado e ausência de legitimidade de muitos governantes com a consequente utilização de meios excessivos de controlo social, corrupção disseminada em vários quadrantes da sociedade, incapacidade de provimento de bens e serviços básicos de saúde, educação, segurança social e habitação, economias estagnadas sem qualquer perspetiva de evolução e 
criação e distribuição de riquezas; por vezes, apropriação da estrutura pública por fações étnicas, políticas ou económicas (Delgado 2016, 329).

Definitivamente, é essa insegurança estrutural e institucionalizada que o Estado pós-colonial qualifica de segurança nacional, na ausência da criação de condições para uma segurança objetiva, definindo-se como "um estado de espírito confiante e tranquilo resultante da capacidade de um país de utilizar a força para reprimir uma agressão estrangeira e também de promover a paz civil e a concórdia nacional graças à satisfação das necessidades políticas, económicas, sociais e culturais dos cidadãos, incluindo a proteção física dos homens e dos seus bens e a garantia do exercício dos direitos e liberdades fundamentais do homem e do cidadão (Jobert I985, p 265).

No entanto, segundo Luís Saraiva (2010, I06), "as ameaças à segurança africana poderão vir a ser reduzidas se os seus países mais em risco entrarem na via do desenvolvimento. Para isso são necessárias estruturas de segurança que possam garantir as condições mínimas para o sucesso de programas de desenvolvimento .

Todavia, a vulnerabilidade de alguns países africanos mais fragilizados reflete-se segundo ainda o autor "na sua incapacidade para enfrentar as redes de droga, na escassez de meios navais para se opor às redes de migração clandestina e para protegerem as riquezas das suas águas, e também na dificuldade em conseguir adequar as suas leis e sistemas ao acompanhamento e combate do fenómeno terrorista, impedindo-os de colaborar com maior eficácia no esforço de combate da comunidade internacional (Saraiva, 20ıо, I06).

No entanto, considera-se que o paradigma da segurança e defesa são das mais importantes vertentes em que África terá que envidar esforço para o desenvolvimento das mesmas, tanto na vertente das capacidades militares africanas, tanto ao nível técnico-militar como, em geral, nas competências no âmbito da manutenção da paz e da segurança. Deste modo, vários teóricos bem como analistas e políticos têm sido unânimes na ideia de que aquelas estão aquém das necessidades de África (Saraiva 20I0, I07).

Podemos considerar que os fatores históricos como os processos de descolonização, a Guerra Fria, as crises e as guerras civis que se seguiram à queda do muro de Berlim foram fatores que criaram obstáculos a um desenvolvimento das capacidades militares em sincronia com os processos mundiais (Saraiva 2010, I07).

Deste modo permitiu com que a fragilidade que se verifica nas instituições em África até mesmo na União Africana, considerada o maior centro político do continente, fosse tida como uma instituição sem grande prestígio a nível do próprio continente por constituir diversos problemas de ordem 
material e organizativa.

Neste contexto, considera-se que após o período bipolar, o continente africano deixou de ser relevante, os conselheiros e peritos militares abandonaram a região e os meios militares e a ajuda financeira começaram a declinar. Politicamente, desde a independência dos seus dirigentes coloniais europeus, África traz-nos à ideia a ocorrência de imagens de guerras civis, fome, corrupção generalizada, governos incapazes, golpes de Estado e violações dos direitos humanos (Thaker 2006, I0).

Segundo Augusto Trindade (2006, 7), "o pouco desenvolvimento das capacidades militares africanas encontram-se diretamente ligado à problemática do desenvolvimento em África .

E, apesar de como afirma, os sinais da rotura em África serem positivos, igualmente muitos países terem a sua dívida externa perdoada nos anos mais recentes e de ter sido consagrado ao ano de 2005 o lançamento do cumprimento dos Objetivos de Desenvolvimento do Milénio, a verdade é que África falhou no cumprimento desses objetivos previstos como meta para o ano de 20I5. Deste modo, "os próximos anos continuarão a se debater com algumas contradições: entre a marginalização e a emergência política; entre a retomada global e a falência de vários Estados; e entre a redução da conflitualidade por contraste com o espectro da continuidade dos conflitos (Trindade 2006, 7).

É a instabilidade que se alastra na maior parte do continente que pode pôr em causa os esforços de pacificação, de democratização e de recuperação económica nas respetivas regiões (Trindade 2006, 8).

Deste ponto de vista, considera-se que sem a paz, sem o exercício da democracia por parte dos Estados, será difícil olhar para o sonho de integração de uma África única caraterizada como os Estados Unidos de África.

Neste domínio, é imperiosa a reconstrução do Estado, das instituições a acima de tudo a potenciação do capital humano, uma vez que se trata de Estados à beira da falência por estarem em guerra, ou por terem saído recentemente de conflitos altamente destrutivos.

Como forma de anular as debilidades sistémicas, uma das grandes prioridades deverá então ser a mobilização e administração correta dos recursos existentes no continente, em que a primeira prioridade deverá ser o estabelecimento da paz e da segurança, pois a economia só prospera fora de ambientes de crises ou guerra (Trindade 2006, II).

Uma outra prioridade refere-se ao investimento no fator humano através da formação profissional, pela escolarização e pelo fomento na área da saúde (Trindade 2006, II). 


\section{A dialética do poder político em África}

A interdependência do vetor da segurança que acabamos de analisar é atualmente uma das principais temáticas abordadas no contexto das Relações Internacionais africanas, absorvendo a diretriz dos padrões de governação do "homem político africano, como se a cúpula para encontrar as soluções extraordinárias para os problemas do continente estivesse na exata medida da relação pontual do seu comando. Constantemente, o problema do poder em África assume especial relevo nas zonas de conflitualidade local dissimulada, principalmente nas áreas conjunturais de valor estratégico acrescentando, onde se assiste a uma proliferação dos conflitos regionais e intraestatais, conduzindo a um subdesenvolvimento estrutural grave e, em certa medida, à falência dos Estados que as norteiam (Bernardino 200I, I33).

Após as emancipações, que acarretaram uniformidades políticas à soberania mas não em liberdade e cidadania aos seus nativos, dirigentes africanos amordaçaram as divergências, governando de forma despótica, quando não cruel.

Por conseguinte, "em vez de ser a vontade do povo a gerar o poder e legitimá-lo, é a força que cria o poder, legitimando-o e engendrando a vontade do povo (Tshiyembe 20I4, I8). A incapacidade ou impossibilidade de conviver com a adversidade levou a conflitos. Poder-se-á dizer que tal foi a inclinação dos dirigentes perante os obstáculos dissimulados e diante da heterogeneidade cultural.

Afluente de instituições desiguais, essa diversidade repercutiu se em diferentes entendimentos de valores e leis, assim como de procedimentos e de direitos relativos à vida humana. Contudo, estes anátemas do domínio conquistado continua a ser propriedade exclusiva dos seus detentores, entretanto, não é repartido e não tem tendência para mudar de titular (Tshiyembe 20I4, I8).

As virulências desta realidade, altearam o desafio dos dirigentes para um modelo factual segundo o qual "o ideal é a preservação do poder, preservação essa que se converteu no principal interesse nacional, se não no exclusivo (Tshiyembe 20I4, I8).

Logo, desde então, na ótica dos governantes, o objetivo máximo do Estado não é nem o desenvolvimento económico e social, nem mesmo a unidade nacional, mas sim o poder (Tshiyembe 20I4, I8).

Na nossa perspetiva, essa ideologia de segurança é a mina de insegurança nacional, visto cativar o poder político, o exclusivo componente constitutivo do Estado e a condição basilar da paz sociável e da consonância nacio- 
nal.

Desta forma, ainda que de forma puramente empírica, o mesmo autor acrescenta que esta veracidade é aplicada através do resultado de dois motivos, na qual o primeiro "assenta o poder africano como uma relação dialética de dependência externa que escapa ao controlo do Estado pós-colonial (Tshiyembe 20I4, I8).

Em segundo lugar, o "verdadeiro inimigo, se não mesmo o exclusivo do poder africano não é esse inimigo externo hipotético tão denegrido. O verdadeiro inimigo do poder africano é efetivamente o povo organizado que lhe recusa a sua legitimidade política (Tshiyembe 20I4, I9).

Apologista da mesma ideia, Georges Balandier apresenta a sua teoria gerada do poder e a imagem do domínio em África, de forma genérica, comparando o poder à montagem teatral. E carateriza a África da seguinte maneira:

Em África, existe uma imaginária percebida para exprimir o poder. No meu livro, Le pouvoir en scéne, penso mostrar como o político é constantemente fabricante da sua própria imagem para exercer o que se chama poder... Há um autor (mal conhecido) que comentou Shakespeare propondo o conceito de teatrocracia... que ilustra que para além dos regimes, das constituições particulares [...] há em comum, nestes todos regimes, a «mise en scéne», o regime geo-teatral: o regime do facto que o político é também um ator... A ordem do político é favorável à esta representação da imagem. Este é o caso do poder tradicional, porquanto são poderes potencialmente em imagem [...] existe um cenário e os atores desempenham cada um papel, onde está colocado em famoso o político... e é cíclico [...] É o caso do Benim, onde o soberano morre, diz-se: a escuridão caiu no país; a justiça, a ordem desapareceu [...] Daí, a necessidade de restituir a luz, a justiça ou a ordem [...] Há toda uma estrutura, uma maquinaria, cujos atores intervêm para restituir a luz ou a ordem desaparecida (Balandier I989, I9).

A complexificar a análise desta circunstância política de África, permite considerar que todas as forças repressivas (ou na sua maioria), designadamente, o exército, a guarda, a polícia, as milícias populares e os serviços secretos, são constituídas, treinadas, equipadas e financiadas pelos países orientais e ocidentais, essas potencias estrangeiras dispõem da capacidade tanto de proteger o poder, quanto de desestabilizá-lo, ou ainda de invertê-lo, pura e simplesmente, em função dos seus principais interesses nacionais (Bernardino 200I, I33).

O mesmo tipo de argumento explica o chefe do batalhão Le Seigneur: "Esses exércitos materializam soberanias novas em espaços imensos, sobe- 
ranias sobre as quais urge infletir orientação política, e que desempenham um papel determinante na sobrevivência dos governadores em exercício ou na sua convicção. Esses órgãos liliputianos revelam-se, assim, forças políticas essenciais da África negra que devem ser controladas (Guillemin I979, 8).

O poder político enquanto manifestação da força pública, e cujas prerrogativas tinham sido utilizadas pela autoridade colonial, afetou mais profundamente os líderes políticos africanos. Neste âmbito, a ideia do poder político enquanto bem comum não se enraizou nas mentes dos líderes da humanidade. Em contrapartida, foi entendido como a força de um homem ou grupo que impõe a sua conceção do mundo ao conjunto da sociedade que governa (Tshiyembe 20I4, 26).

Esta politização das diferenças pode parecer, à partida, incoerente ou contraditória com o facto de muitos líderes africanos defenderem como tarefa primordial o desenvolvimento de uma unidade nacional e uma ideia de uniformização para a construção da Nação. No entanto, são processos que se desenrolam simultaneamente e que estão interligados entre si (Ferreira 20I4, I8).

Todavia, tal como constata P.F. Gonidec, essa realidade quotidiana não atenua as aparências constitucionais democráticas que proclamam o princípio segundo o qual a "soberania pertence ao povo (Gonidec I983, 70).

A título de exemplo, a Constituição do Gabão declara instaurar o "governo do povo pelo povo e para o povo (artigo $2^{\circ}$ ). Profícua no mesmo sentido, a Constituição da Guiné-Bissau sublinha que a soberania nacional da República da Guiné-Bissau reside no povo (art. $2^{\circ}$ ). Ao passo que a da Nigéria indica que o povo tem o poder de definir as regras do jogo político adotando uma constituição, a lei suprema do Estado (art. Iffl da Constituição de i979).

Dentro de um contexto de expressiva perenidade, percebe-se que as constituições africanas são vistas como mera papelagem correspondente à vontade política da equipa dirigente do momento.

Deste modo, Y. Faure comprova que a constituição não é estabelecida com o desígnio de reconhecer a simplificação do poder ao serviço da coletividade ou das diversas ficções jurídicas ou intelectuais que lhe são subjacentes (a nação, o país, a pátria, o bem comum, o interesse geral). Mas é exercida com vista à imobilização das funções políticas, da localização definitiva dos agentes para a relação [...] (Faure I98I, 34).

A constituição africana é uma técnica da supremacia política, preconiza o "detentor vitalício do poder (que deve perdurar durante a vida de uma pessoa e não além disso). Quando, por conta das crises, os militares usurpam o poder, não exigem o livre consentimento do povo para exercê-lo. Pres- 
supõem que o mesmo se encontra no estado pueril e decidem substituí-lo, alegando que as suas revoltas foram ditadas pela vontade de proteger o povo contra a violência dos dirigentes destituídos do poder (Faure I98I, 35).

Porém, as dificuldades de lidar com a assimetria e a heterogeneidade social derivam das disfunções e da conflitualidade no seio do Estado apropriado por grupos e atores, que importará identificar e nomear, sem o que se pode falar sem cessar do papel predatório dos Estados, ao mesmo tempo que tal perde significado. Em contrapartida, pragmaticamente, identificar os donos do Estado, chefes étnicos ou de qualquer outra clientela e fidelidade, obrigará, talvez, a dialogar com eles na perspetiva do compromisso possível na construção de políticas preventivas da conflitualidade (Nascimento I992, 20).

Estas questões reconduzem nos à problemática da arquitetura política em África. Num prazo concebível, os projetos de integração ou de refundação política de África não deverão apagar os Estados e as entrementes criadas identidades nacionais. Porém, por algum tempo, os Estados serão, sobretudo, o elo de ligação externa em desfavor da ligação estreita ao tecido social com cujo desenvolvimento e proteção (quiseram e) deviam estar comprometidos (Nascimento I992, 22).

É neste âmbito que se idealiza que a gestão do poder político em África afigura-se como um instrumento meramente utópico na definição da partilha de segurança que beneficia uns em detrimento de outros à margem da distribuição de valores políticos e de reconhecimento das dissensões internas que transportam para si uma divisão profunda para toda África.

\section{Acção da Organização da União Africana na Segurança em África}

A criação da União Africana, em 2002, foi um passo importante para alterar o panorama de atuação nos conflitos africanos e abandonar a conceção rígida de soberania e não intervenção defendida pela predecessora OUA.

Assim, a União Africana preconiza o regime mais intervencionista de uma organização regional, afirmando no seu ato constitutivo o direito de intervenção em circunstâncias graves, que incluem crimes de guerra, genocídio e crimes contra a Humanidade (African Union 2000).

Neste contexto, a Carta da Organização da Unidade Africana de I963 não continha um mecanismo muito evoluído de segurança coletiva, não obstante ser considerada uma organização regional colaboradora do Conselho de Segurança em matéria de paz e segurança regionais (Delgado 20I6, 326). 
Muito embora não se possa atribuir a limitações jurídicas as causas dos três tipos de conflitos que eclodiram em África antes do fim da Guerra Fria - nomeadamente, os conflitos interestaduais, conflitos internos e conflitos anticoloniais -, a prazo, a principal contribuição da OUA radicou precisamente no apoio positivo que forneceu para a concretização dos processos de libertação nacional (Dugard 1967). Ela manteve-se conservadora no que toca a intervenções em questões internas, adotando um princípio quase absoluto da não intervenção (Murithi 2005), e ineficaz na resolução dos conflitos regionais.

Contudo, constata-se que a segurança em África é considerada por quase todos uma prioridade estratégica, pois, sem segurança não existe desenvolvimento sustentável. Não a segurança clássica do Estado ou das suas Organizações, mas a dimensão da segurança "real”, sentida e centrada na pessoa humana5. Tal dimensão abandona o conceito estereotipado de identidade de segurança nacional, centrado no Estado, para o de segurança humana, centrado nas sociedades, nas populações e no ser humano. (Bernardino 2008, 8o).

Este novo paradigma de segurança humana é visto como sendo aquele que reúne múltiplos pressupostos securitários que afetam a paz e a segurança mundiais, definido como:

Segurança humana significa proteger liberdades fundamentais. Significa proteger pessoas de ameaças e situações críticas e omnipresentes. Significa utilizar processos que assentem nas qualidades e aspirações das pessoas. Significa criar sistemas políticos, sociais, ambientais, económicos, militares e culturais que juntos possam garantir as bases para a sobrevivência, subsistência e dignidade das pessoas (United Nations 2003, 4).

O conceito de segurança atinge desta forma uma terceira dimensão ${ }^{6}$ que veio priorizar as populações humanas como objeto, alargar o âmbito de

5 A segurança humana consiste na forma como o povo vive e respira numa sociedade que faz livremente as suas escolhas variadas e tem acesso ao mercado e a oportunidades socias.

6 Até ao momento, a história do mundo contemporâneo conheceu três dimensões do conceito segurança: uma primeira visão tradicional que se cingia à proteção do território de um Estado de ameaças militares externas - a chamada segurança nacional (ver Kelsen, Hans. I957. Colletive Security under International Law. Washington: United States Government Office); uma segunda noção que, como já vimos, através do desenvolvimento de um sistema de segurança colectiva, transformou uma redutora delimitação do conceito ao princípio da soberania estatal numa ideia de segurança internacional; e, por fim, o advento da segurança humana sustentável, último estádio de desenvolvimento do conceito e adotado pela ONU nos últimos documentos oficiais e consequente estratégia operacional. 
aplicação da segurança coletiva7 e incluir um rol cada vez maior de situações na lista de ameaças à segurança e paz internacionais.

As capacidades africanas enfrentam, ainda, um variado leque de desafios, entre os quais se destaca a materialização dos novos planos da UA relativos à paz e à segurança africanas. Esses desafios constituem uma parte importante do conjunto de fraquezas que África tem que saber vencer (Saraiva 2014, I08).

De fato, o Ato Constitutivo da União Africana, inicialmente denominada Organização de Unidade Africana, no seu artigo $3 \mathrm{ffl}$, designado como "Objetivos", na alínea f, afirma que é obrigação dos Estados signatários do Ato Constitutivo da União Africana "promover a paz, a segurança e a estabilidade do Continente” (African Union 2000).

Este novo modelo de segurança desenvolveu-se no sentido de conferir uma maior proteção e grau de consistência, próximo das populações, pois estas são constantemente afetadas pelos vários conflitos regionais.

Luís Bernardino defende a necessidade de se adotar uma visão de segurança que ultrapasse em muito a segurança do Estado, focalizando a segurança no indivíduo, na pessoa e criando sistemas de segurança que protejam diretamente as populações (Bernardino 2008, 8I). O que nos leva a sublinhar que a intervenção da segurança humana constitui o polo fulcral para estabilidade de qualquer nação.

Couto Lemos apud Saraiva (20I4, I79) afirma que "os processos de segurança e de desenvolvimento devem estar intimamente ligados pois um depende do outro. Se a segurança não está omnipresente, se os cidadãos notarem, as pessoas estarão mais predispostas a aceitar a entrada de fatores de estabilização para que seja um dado adquirido.

Focando-se nos interesses da segurança africana, o ato constitutivo da união africana no seu o artigo 4 ffl (Princípios) do mesmo documento, nas alíneas "e" a "j" alerta para a necessidade de haver uma resolução por via pacífica, dos conflitos entre Estados-Membros da União através de meios apropriados que sejam decididos pela Conferência da União (e); proíbe o uso ou ameaça da força entre os Estados-Membros da União (f); declara que a UA tem o direito de intervir num Estado-Membro em conformidade com uma decisão da Conferência em situações graves, nomeadamente crimes de guerra, genocídio e crimes contra a humanidade (h); defende a coexistência pacífica dos Estados-Membros da União e seu direito de viver em paz e em segurança e de procurar ajuda, através da Conferência da UA, assim como o direito de não interferência através de um Estado-Membro nos assuntos internos de

7 Princípios que já se encontravam vertidos nas diretrizes da Responsabilidade de Proteger. 
outro Estado-Membro (i) aliado ao direito dos Estados-Membros de pedirem a intervenção da União, com vista à restauração da paz e segurança (j) (African Union 2000).

Entende-se deste modo, que estes princípios fundamentais da União Africana, no cômputo da paz e da segurança do continente africano, proporcionou a criação de normas ou instrumentos jurídicos ou de caráter político, como são os casos do (Delgado 2016, 326):

- Protocolo que estabelece o Conselho de Paz e de Segurança (CPS) (2002) (Gumedze 20II, 327);

- Protocolo de Não-Agressão e Defesa Mútua (2005);

- Carta Africana sobre Democracia, Eleições e Boa Governação (2007);

- Convenção para a Eliminação do Mercenarismo em África (I977);

- Tratado para a Criação de uma Zona Livre de Armas Nucleares em África (I996);

- Convenção Africana para a Prevenção e Repressão do Crime de Terrorismo (I999);

- Carta Africana dos Direitos Humanos e dos Povos (I98I);

- Instrumentos regionais de proteção dos refugiados (I969), das crianças (I990), das mulheres (2003), da juventude (2006) e de deslocados internos (2009).

No mesmo diapasão, não deixam de justificar esta presença os instrumentos regionais de promoção da integração económica através de criação da Comunidade Económica Africana (I99I), de combate à corrupção (2003), o de promoção dos valores do serviço público (20II), e o relacionado com a proteção da(s) cultura(s) africana(s) (2006) (Gumedze 20II, 327).

Stephan Klingebiel, um politólogo alemão especialista em questões de desenvolvimento em África, desenvolveu por si só como a dinâmica correntemente envolvida com a assistência externa em África se refere em larga escala às capacidades militares (Klingebiel 2007, 7I).

Pois que, as instituições erguidas por África ou pela comunidade internacional não têm sido competentes ou não têm tido a vontade suficiente de intervir militarmente em situações de extrema emergência para proteger as populações civis (Klingebiel 2007, 7I).

Entretanto, foram expressas muitas dúvidas sobre a razão de ser de determinadas ações militares e questionados os motivos que levaram a iniciativas e ações militares por atores externos em África. Daí os principais problemas da anterior organização africana, a "OUA", os quais seriam devidos aos princípios inibidores da igualdade soberana e da não interferência nos 
assuntos de outros Estados-membros (Klingebiel 2007, 7I).

Nicolle Gnesotto ${ }^{8}$, especialista em segurança africana, defende que “a pobreza crescente em África é vista como um dos mais graves fenómenos que se constituem como obstáculo ao combate à fraqueza das capacidades africanas em matéria de paz e segurança. E, na verdade, sem um Estado forte, capaz de assumir as funções reguladoras, os países africanos não serão capazes de sair da fragilidade económica (Gnesotto 20I7, I7).

No entanto, Charles Goerens destaca que a constituição ou reconstituição dessa capacidade de garantir a paz e a segurança não deverá ser sinónimo de burocracia excessiva (Goerens 2007). Tal quadro contribui para um sistema regional com índices de ineficácia ainda insuficientes para garantir a segurança continental através da organização da União Africana.

Said Djinnit, embaixador e político argelino, quando era Comissário para a Paz e Segurança da Comissão da União Africana (UA), afirmou, na sua opinião perante os parlamentares da UEO, reunidos em sessão plenária em Dezembro de 2005, que "a nova determinação ilustrava a ambição do continente, mas também os limites daquilo que África pode fazer. Ou seja, sozinha não dispunha dos recursos humanos necessários para empreender esse imenso mandato de paz e segurança", afirmou, referindo-se ao desafio de África dirigir o seu próprio destino (Assembly of Western European Union 2005).

Nota-se que um dos maiores problemas com que o continente Africano continua a se deparar está na procura da consolidação da paz e segurança. Neste sentido podemos afirmar que os Estados africanos deverão procurar manter e apoiaram-se nas recomendações e resoluções distribuídas nas cimeiras da União Africana, nos Conselhos Executivos, nos Comitês Especializados que, no caso presente, é o Conselho de Paz e Segurança da União Africana, bem como nas Organizações Regionais Africanas, políticas, económicas e militares (Gnesotto 2007, I7).

A União Africana, apesar de todas as suas debilidades se enquadra num contexto de relativa estabilidade e aprendizagem, e é considerada ainda a principal organização regional do continente africano. Embora dentro de um contexto de clara manutenção e perenidade de conflitos armados, que convive com inúmeras situações de instabilidade não pouco dissimulada, a temática da segurança no Continente africano adquire especial realce (Gnesotto 2007, I7).

Por esse facto, constata-se que, apesar dos incessantes esforços da

8 Nicolle Gnesotto foi diretora do Instituto de Estudos de Segurança da União Europeia entre 2002 e 2007 . 
UA e dos seus comitês especializados, a paz e a segurança político-militar no continente constituem uma ferramenta embrionária apática suscitando o projetar de alguns cenários facilitadores de predisposição ao conflito, na qual o funcionamento de escolas institucionais de prevenção, gestão e resolução de conflitos se assume como fulcral, visando uma abordagem a um tempo preventiva e simultaneamente com capacidades na gestão e resolução de crises (Gnesotto 2007).

No entanto, o futuro da ação global da segurança africana pautar-se-á por métodos de revisão estratégica baseados em práticas bem-sucedidas, mais do que na criação de novas funções de segurança ou de novas capacidades militares que muitas das vezes são criadas para proteção de certos grupos.

Deste modo, apesar de que certos problemas de segurança que marcam o continente não constituírem ameaças convencionais e diretas aos seus congéneres continentais ou para a segurança internacional, os conflitos internos e a reduzida capacidade de controlo territorial, de um lado, e a corrupção e fragilidade económica do Estado, do outro, fazem com que se possa transformar num problema com capacidade de externalização e que coloca riscos para a segurança dos seus vizinhos, através da promoção indireta da fuga de pessoas para Estados fronteiriços a zonas de conflito ou da aceitação da utilização do seu espaço como base de criminosos ou de agremiações político-militares hostis a terceiros (Delgado 2016, 324).

\section{Conclusões}

A dialética da compreensão da realidade do vetor da segurança, que inferimos neste artigo, constitui uma problemática inédita para o continente africano, evidencia que a eficácia de todo o sistema de segurança regional africano é afetada pela fragilidade do Estado e ausência de legitimidade de muitos governantes, com a consequente utilização de meios excessivos de controlo social, corrupção disseminada em vários quadrantes da sociedade, incapacidade de provimento de bens e serviços básicos de saúde, educação, segurança social e habitação, economias estagnadas sem qualquer perspetiva de evolução e criação e distribuição de riqueza; por vezes, apropriação da estrutura pública por fações étnicas politica ou económicas (Delgado 20I6, 329).

Contudo, todos esses aspetos cooperam para um sistema regional com índices de eficiência ainda insuficientes para garantir a segurança continental. Deste modo, os ambiciosos mecanismos previstos e a robustez que possuem comparativamente ao sistema universal ainda não puderam ser explorados 
integralmente por diversos motivos, conforme refere Delgado (20I6, 33I), "relacionados com a disponibilidade de meios financeiros e logísticos-militares, à titubeante adesão aos grandiloquentes e vanguardistas valores e princípios, problema organizacionais, falta de articulação económica, naturais interesses nacionais e estratégicos particulares, dentre vários outros".

Outro aspeto fundamental, que se prende com o paradoxo surpreendente do vetor da segurança em África, reside no facto de que não é a vontade do povo que cria o poder e o legitima; pelo contrário, é a força que cria o poder, o legitima e fabrica a vontade do povo (Tshiyembe 20I4, II2). Assim, a segurança se carateriza como frágil, escassa em virtude do não cumprimento das normas legitimadas pelas constituições para uma gestão eficaz.

Assim, o poder obtido nesses moldes permanece propriedade privada dos seus detentores, não é partilhado, e não contempla sequer uma alteração do titular, percebe-se de certo modo que a mesma se apresenta como um vetor-chave da violência política no continente dentre outros fatores.

Não obstante a isso, a reação negativa em cadeia desses fenómenos no espaço político levou-nos assim a definir o Estado pós-colonial como um poder autocrático e feudal de tendência monárquica que, no entanto, reina sobre uma república escrava e cujo beneplácito se configura numa utopia.

Relativamente ao pequeno contributo sobre a União Africana, é visível que a sua gritante ineficácia é, ironicamente, criticada pelos Estados-membros por vezes com algum excesso de ingenuidade. Efetivamente é curioso constatar que vários Chefes de Estado africanos ignoravam que a UA representa uma organização intergovernamental e que, neste sentido, o seu campo de ação é limitado pelos poderes que lhe conferem os Estados-membros.

Todavia, o mesmo seria dizer que estes ainda não compreenderam que são eles próprios os agentes desta paralisia, e que por mais que o digam ou façam, o fracasso da UA representa o seu próprio fracasso. Assim, é preciso que o continente crie uma combinação de vontades e ações dos indivíduos com vista ao prosseguimento de objetivos determinados ou realização de determinados fins para mudança urgente de um novo paradigma. É preciso que se ative com principal pendor a Arquitectura Africana de Paz e Segurança (em inglês, APSA, Arquitetura de Paz e Segurança da União Africana), que foi elaborada com base nas estruturas, nos objectivos, princípios, valores, processos de tomada de decisão em matéria de prevenção, gestão e resolução de crises e conflitos, reconstrução e desenvolvimento pós-conflito no continente, assim como o Protocolo Relativo ao Estabelecimento do Conselho de Paz e Segurança da União Africana9, que descreve os vários componentes da APSA e suas

9 Foi aprovado em Julho de 2002, em Durban, e entrou em vigor em 2003. 
respectivas responsabilidades a fim de ser uma organização mais presente na gestão do continente.

\section{REFERÊNCIAS}

African Union. 2000. "Constitutive Act of the African Union”. Lome, Togo: African Union.

Assembly of Western European Union. 2005. Proceedings Vol. IV, Fifty-First Session, First Part, December 2005 - Minutes and Official Report of Debate of Seventh Sitting.

Balandier, Georges. I980. Le pouvoir sur scènes. Paris: Ballard.

Bernardino, Luís. 2008. Estratégias de intervenção em África: uma década de segurança e defesa na comunidade dos países de Língua Portuguesa. Lisboa: Editorial Prefácio.

Cabral, Amílcar. 2008. Documentário “África Minha”. Apresentação de António E. Duarte da Silva. Lisboa: Cotovia.

Chabal, Patrick, and Jean-Pascal Daloz. I999. Africa works: Disorder as political instrument. London: The International African Institute.

Cilliers, Jakkie, and Timothy Sisk. 2013. Assessing long-term state fragility in Africa: Prospects for 26 'more fragile' countries. Pretoria: Institute for Security Studies.

Collier, Paul. 20Iо. Os milhões da pobreza: Por que motivos os países mais carenciados do mundo estão a ficar cada vez mais pobres?. Lisboa: Casa das Letras.

Delgado, José Pina. 20I7. "Segurança em África". In Segurança Contemporânea, 32I-336. Lisboa: Pactor.

Diamond, Larry. I988. "Introduction: Roots of failure, seeds of hope". In Democracy in developing countries: Africa - Vol. II. London: Adamantine Press.

Fatton, Jr. Robert. I990. "Liberal democracy in Africa". Journal Political Science Quarterly I05 (3): 455-473.

Faure, Yves. I98I. "Les Constitutions et l'exercice du pouvoir en Afrique noire". Politique Africaine I98I (I): 34-52.

Ferreira, Patrícia. 20I4. "”stados Frágeis" em África: a intervenção externa nos processos de construção do Estado (Statebuilding) e da paz (Peacebuilding)". PhD thesis, Instituto Superior de Ciências do Trabalho e da Empresa. 
Gaeta, Feliz. I994. "État-nation face au processus de transition en Afrique noire". Omaly Sy Anio I994 (3I-33): 713-729.

Gnesotto, Nicolle. 2007. "Préface". In Sécurité et développement de l'Afrique: une nouvelle approche pour l'EU. Paris: Institut d'Études de Sécurité.

Gonidec, Pierre-François. "Esquisse typologique des régimes politiques africaines”. Pouvoirs I983 (25) : 63-79.

Guillemin, J. 1979. "Coopération internationale: politique militaire de la France en Afrique noire et Madagáscar". PhD thesis, Université de Nice.

Gumdze, Sabelo. 20II. The peace and security council of the African Union: Its relationship with the United Nations, with the African Union and with sub-regional mechanisms. Abo: Abo Academy University Press.

Hugon, Philippe. 2009. Geopolítica da África. Rio de Janeiro: FGV de Bolso. Jobert, Michel. I985. Maghreb, à l'ombre de ses mains. Paris: Albin Michel. Klingebiel, Stephan. 2007. "Peace and Security Policy of the African Union and the Regional Security Mechanisms". In Africa and Fortress Europe, 7I84. Alderhot: Ashgate.

Moller, Bjorn. 2007. “The security sector: leviathan or hydra?”. In African Security Governance: Emerging Issues, I9-36. Johannesburg: Wits University Press.

Murithi, Timothy. 2005. The African Union: Pan-Africanism, Peacebuilding and Development. Aldershot: Ashgate.

Nação e Defesa. 20I2. Revista de Assuntos Políticos Económicos Científicos e Militares do Instituto da Defesa Nacional 2012 (I3I).

Nascimento, Augusto. I992. "Vetores políticos e operacionalização da segurança em África”. Nação e Defesa: Revista de Assuntos Políticos Económicos Científicos e Militares do Instituto de Defesa Nacional I992 (I3I): II26.

Saraiva, Luís Eduardo. 20I0. As Relações entre Angola e a Guiné-Bissau. Comunicação apresentada na Conferência sobre A Política Externa de Angola no novo contexto internacional na Universidade Lusíada de Lisboa, em I5 de Abril de 20I0. p.96.

Saraiva, Luís Eduardo. 20I4. Segurança e desenvolvimento União Europeia-África: o caso da Guiné-Bissau. Lisboa: Imprensa Nacional Casa da Moeda.

Thaker, Pratibha. “Transafrican watch”. Aspenia 2006 (29-30): II-30.

Trindade, Augusto. 2006. Desenvolvimento económico, integração regional e ajuda externa em África. Lisboa: Instituto Superior de Ciências Sociais e Políticas. 
Tshiyembe, Mwayila. 20I4. O Estado pós-colonial: factor de insegurança em África. Luanda: Edições Mulemba.

Veríssimo, Gilberto. 20I4. "A posição estratégica de Angola no Golfo da Guiné". $\mathrm{PhD}$ thesis, Universidade de Lisboa.

\section{RESUMO}

A segurança desde os tempos primórdios constituiu em permanência e desde sempre uma preocupação do homem na vivência em sociedade como condição fundamental. Contudo, na procura deste desiderato, o homem estabeleceu alianças, acordos, parcerias e múltiplas formas de cooperação para resolver os seus determinados problemas de segurança, que em determinados contextos históricos foram basilares para o curso da própria Historia analogamente para a sobrevivência das sociedades. Neste contexto, África afigura-se como o continente berço da humanidade, onde o nível de insegurança qualifica-se como crítico, que em nossa opinião permitiu estudar os vectores desses acontecimentos. Por sua vez, procuramos articular e explicar à luz das Relações Internacionais Africanas, os principais vectores estratégicos que materializam uma abordagem diferenciada sobre a segurança em África, desvendando as raízes dos problemas que o assolam, escrutinando a situação, identificando os constrangimentos e as ameaças, antes de anunciar um conjunto de propostas para a solução dos diversos problemas que se manifestam no continente.

\section{PALAVRAS-CHAVE}

Segurança; Política Externa; Cooperação, África e Forças Armadas.

Recebido em 12 de dezembro de 2016. Aprovado em 25 de junho de 2016. 